\title{
A PROPÓSITO DE LA CONTINUIDAD DE LO MEDIEVAL EN LA VIDA RELIGIOSA: LAS MAGDALENAS
}

\author{
Antonio LINAGE CONDE \\ Universidad de San Pablo-CEU \\ Madrid
}

La salvaguardia de to esencial es un problema siempre planteado al tener lugar un cambio en una institución que permanece y no hace explícita la declaración de ruptura con el pasado. En la Iglesia Católica se ha suscitado de manera un tanto dramática en torno a las consecuencias del último Concilio, habiendo sido la postura oficial y mayoritaria la de la continuidad, siendo la contraria la de la exigua minoría rebelde a aquél, aunque las manifestaciones de los más extremosos sostenedores de la mutación, de hecho no fueran compatibles con tal reconocimiento.

Mas la materialización muy concreta de las instituciones particulares en la Iglesia latina ha determinado además de siempre el surgimiento de la misma problemática pormenorizada para cada una. Concretamente en las órdenes y Congregaciones religiosas. Cierto que su proliferación tuvo sobre todo lugar en el nuevo régimen, y que el trance que a su vez ellas hubieron de vivir en la segunda mitad del siglo XX -hasta entonces escasamente puesta en tela de juicio su continuidad- quedó inmerso en el global a que empezábamos aludiendo(1). Pero muchas de las anteriores, modernas, medievales y aun antiguas o cuasi, la mayoría estamos tentados a decir, habian sobrevivido. Saltando a la vista que, por mucho que se haya querido insistir en la fidelidad a la inspiración fundacional, ora en los móviles ora en la manera de 
vivir y hasta en la mentalidad de la propia consagración, la necesidad de mutación correlativa al devenir del tiempo histórico sin más no ha podido esquivarse. Mas llevando en cada caso consigo el germen de una zozobra y la mecha de alguna polémica.

Nosotros vamos a limitarnos aquí a dar noticia dentro del movimiento tendente a la "rehabilitación", entonces concebida exclusivamnete por la vía del arrepentimiento, de las mujeres de conducta irregular(2). Una situación, se comprende, permanente, que hubo por lo tanto de dar lugar a remedios igualmente constantes aunque variados, dependiendo la mutación o no de la correlativa de las circunstancias temporales. Ejemplo singular, en la Edad Moderna, fue un monasterio aislado en París(3), el de las Filles de la Madelaine o Madelonnettes, con cuatro clases de "religiosas" o acogidas, temporales o permanentes, pero a cargo siempre, a guisa de tutelado, de una congregación distinta(4). Casa sin embargo la tal, por mucho que pueda chocarnos, que podía ser considerada cual una supervivencia de una tradición medieval densa. Al menos desde Fulques de Neuilly, el predicador de la Cuarta Cruzada, quien convirtió la antigua abadía de Saint-Antoine-des-Champs, en París también, en convento de prostitutas arrepentidas, si bien en 1204, a los dos años de la muerte de aquél, se hicieron cistercienses, con rango abacial al cabo de otros dos. Una solución(5) paralela a la de la erección de congregaciones ad hoc caso del argumento de estas páginas-, como la aprobada por Nicolás III (1277-80), en Marsella, bajo la Regla de San Agustín, allí surgida antes de 1270 por los desvelos del burgués Bertrand, y por cierto de corta duración. Hay que tener en cuenta la exhortación pontificia a tales intenciones y obras, la carta apostólica de Inocencio III Universis Christifidelibus de 29 de abril de 1198.

Y está claro cómo en la postura hacia el fenómeno se conjugaban la moral sexual, el sentimiento del pecado sin más, las estimaciones sociológicas no siempre identificadas con aquélla aunque no llegaran a contradecirla -y eso hasta la víspera de nuestros días-e incluso la ambivalente actitud hacia la mujer y la marginación, tanto de los célibes como de los bien integrados. Un botón de muestra es la exhortación de Vital de Savigny ( $m$. 1122) y Enrique de Lausana (m. 1145) a sus seguidores de casarse con los POENITENTES. Mundo éste de los Wanderprediger que, tanto por el arrebato de su impulso vocacional a esa dedicación como por su contacto con cualesquiera de las gentes pululantes de la época, del nomadismo a la estabilidad, estaba llamado a enfrentarse de cerca con el fenómeno. Cual Roberto de Arbrissel, el fundador de esa orden monástica tan inmersa en los hondones de la femineidad, y tan compleja por eso como ella misma, la de Fontevrault(6), el cual hizo sitio a las antiguas prostitutas en sus tan aristocráticos monasterios ${ }^{(7)}$. Y la capacidad de algún detalle para 
dar qué sentir y pensar: el 10 de Enero de 1309, el papa Clemente $V$ mandaba al obispo de Tolouse bendecir el cementerio de los "penitentes" de la comunidad inmediata al monasterio canonical de San Saturnino. Significativo también resulta el de Fardo de Hugolino (m. 1348), quien dotó la casa de las arrepentidas de Viterbo enclavándola en el mismo que hoy llamaríamos barrio chino de la ciudad, pretendiendo así ser un ejemplo admonitorio para las que continuaban por la mala senda(8).

$Y$ revelador de lo arraigado del fenómeno en las mentalidades coetáneas, su presencia también en Oriente-Acre y Antioquía de Chipre, bajo las reglas respectivas agustina y benedictina, además de los "ejercicios" Avant la lettre que les dedicaban los Hospitalarios en la Semana Santa y la octava de Pascua-, "sin mucho desarrollo, pero datos preciosos", al que todas aquellas fundaciones no pasaban de empresas aisladas sin relaciones entre sí, y por eso, a menudo, acababan por desaparecer a la par que su animador".

Tanto que se diría ser la frecuencia de la titularidad, por otra parte pintiparada, de Santa María Magdalena(9), su rasgo más común.

Pero antes de pasar a ocuparnos del siguiente paso, su familia religiosa ad hoc, conviene que recapacitemos en que sólo la evolución de la vida consagrada en al iglesia occidental puede hacernos valorarla sin más cula un estadio más avanzado. Tengamos en cuenta que el benedictinismo se articuló sobre la única base común de un libro observado aisladamente, la Regla, por más que ello supusiera un Vinculum unitatis más concreto que el precedente monacato de la regula mixta o codex regularum. $Y$ un cotejo con las iglesias de Oriente nos sería fructífero. Mas lo único que aquí nos interesa subrayar es cómo, a los efectos de la mutación de los propósitos iniciales y su encarnación en unas maneras de vivir, una orden puede revelarse más fragil que una casa. Y que sobre todo, a los efectos de la "redención" espiritual y acogimiento material de las prostitutas, y la utilización de las mismas a lo divino diriamos, en beneficio mediato de las necesidades expiatorias y salvíficas de las mujeres y hombres no marginales, las comunidades independientes es posible que en un balance conjunto hayan resultado más fecundas.

Sin embargo, no es posible escamotear, por encima de las turbulencias de sus avatares concretos a lo largo de la Baja Edad Media y aun la modernidad, el íntimo significado de su institución en aquella mentalidad religiosa y social, puesto de relieve, ya a propósito de las Magdalenas de que vamos a dar noticia, por don Jean Leclercq(10), quien nos observa que "si en su seno había ciertos casos en los cuales las arrepentidas recuperaban una excepcional vocación de santidad, manifestándose verdaderas religiosas, en otros, bajo el velo religioso, más bien se trataba de llegar a un nivel mínimo de 
honorabilidad y de vida común con las demás jóvenes, pero indudablemente se había llegado a mostrar que de hecho la vida religiosa estaba abierta a todas las mujeres, y no únicamnete a las que presentaban determinadas garantías de vida honorable, lo cual no era sino una de las manifestaciones del movimiento de promoción de la mujer iniciado en el siglo XII y que algunos historiadores llaman frauenbewegung".

\section{SORORES PENITENTES BEATAE MARIAE MAGDALENAE IN ALLEMANNIA}

Los origenes de esta Orden remontan a los años 1224 a 1227, ocasional fruto de las andanzas en torno a Worms de un canónigo de San Mauricio de Hildesheim, Rodolfo, a quien se le llama por una u otra de ambas ciudades y era entonces capellán del cardenal legado cisterciense Conrado de Urach, quien le hizo nombrar predicador en el sínodo de Maguncia de 1225. En un cruce de caminos se encontró con unas prostitutas, las cuales a sus admoniciones, le prometieron hacer su recta voluntad con tal de que les proporcionara pan, agua y techo, emprendiendo él entonces una campaña en la comarca tendente a tal consecución. Pero desde ese principio con la idea fundacional religiosa, ya que una de sus medidas primeras fue revestirlas de hábito, concretamente blanco, incluido escapulario, y la cabeza descubierta(11). Ya en 1227, Gregorio IX, en Anagni, apoyó su iniciativa, exhortándole al desarrollo de las mismas, pero en monasterios independientes entre sí, bajo la Regula Benedicti y las Constituciones Cistercienses. Cuestión esta de la observancia nominal cuya trascendencia, desde luego relevante en el plano del prestigio, no hay que desorbitar, teniendo en cuenta la impronta tan individualizada de las destinatarias y la circunstancia de haberse ya iniciado en la familia benedictina, vinculaciones parciales más concretas que la Regla misma. Lo cierto es que el mismo Papa, en una bula de 1232, no mencionó ninguna a las nuevas Magdalenas, y en 1237 las sujetó a la de las dominicas de San Sixto de Roma, el convento constituido en 1221 por el mismo Santo Domingo, en cumplimiento del encargo pontificio de reformar algunos femeninos de la Urbe, según la Regla de San Agustín y su mismo modelo primero de Prouille -1206-, pero una vez que éste hubo evolucionado de una misión asistencial de los "frailes predicadores" e incluso predicadora ella misma, a la clausura monástica tradicional(12). Mas las características de la nueva orden eran singulares, de manera que el modelo dominico-romano sólo se pudo adoptar a los efectos del régimen interno. 


\section{LA DUPLICIDAD FALLIDA}

Efectivamente, la Orden se pensó para conventos paralelos, ya que no dobles, de cada sexo, teniendo los hombres la misión de asistir a las mujeres en la dirección espiritual y la administración material y estar el prior por encima de la priora(13), incluso con facultades de excomulgarla. $Y$ según los estatutos de San Sixto, las comunidades masculinas habian de tener al menos un prior, tres sacerdotes y tres legos. El gobierno supremo estaba a cargo del propósito general, elegido en un capítulo general conjunto.

Pero de hecho la rama de los hombres apenas se desarrolló, de manera que en 1237 Gregorio IX tuvo que recurrir a los obispos en cuanto esa carencia hacía difícil llevar a cogüelmo la exención proyectada, y el capítulo de 1280 preveía un sacerdote para cada monasterio femenino y nada más, como en cualquier otra pues de las demás familias religiosas no diferenciadas en tal sentido. Una anomalía por lo tanto en el desarrollo, con referencia a los propósitos iniciales que, si no determinó las crisis, surgidas pronto y a la postre endémicas, pese al incremento numérico también temprano y en buena parte mantenido en la congregación, sí contribuyó a hacer su solución más ardua. Así, el cardenal Juan Boccamazza, legado de Honorio IV en Alemania, decía en 1286, a propósito de ciertas inmoralidades y discordias, nullo ductore nec correctore praevio. $Y$ cuando inmediatamente trató de poner remedio sometiendo todos los conventos alemanes, que eran la inmensa mayoría, más de setenta, al provincial de los dominicos, el canonista Hermann de Minden entonces, las conversaciones y actuaciones tendieron ni más ni menos que a la incorporación de los mismos a la rama dominica femenina, lo que no tuvo lugar por haber sucedido a Honorio, en 1288, Nicolás IV, hostil a los frailes predicadores y que en 1191, por su carta apostólica gaudete et exultate filiaesion, anuló todo lo intentado y llevado a cabo y volvió a las Magdalenas a la situación anterior.

Ahora bien, del máximo interés para la comprensión de las mentalidades medievales y eclesiásticas de todos los tiempos hacia la mujer(14), es el cotejo con ámbitos gemelos, en los cuales la solución pareja fue también problemática desde muy pronto, y a la postre desembocó en una unisexualidad generalizada. $Y$ estamos pensando, por una parte en Fontevrault, cuya rama masculina fue débil y conflictiva(15), y en las brigitinas por otra(16), de las cuales baste decir que, ya en los inicios, Martín $\mathrm{V}$ prohibió los monasterios dobles de las mismas en 1422, si bien Eugenio IV restauró la disciplina anterior por la bula licet suscepti en 1435, en tanto que en la Edad Moderna, de sus varios enclaves en la diáspora, al haberse extinguido en la Suecia originaria por el paso del país al luteranismo, sólo en Rhenania se mantuvo la vieja tradición.

Sin embargo(17), como hemos apuntado, la expansión había sido nota- 
ble, de la Lotaringia y Holanda a Bohemia, a través de todo el mundo germánico comenzado en 1227 por las casas de Estrasburgo, Tréveris y Wurzburgo(18).

\section{DESDE EL ANTIGUO TESTAMENTO A LA MANERA DE VIVIR}

La Regla Pontificia de 1232 comienza dirigiéndose a las Magdalenas con una invocación escrituraria que, desde la Hija de Sión y la Sunamita, pasando por el llanto junto a los ríos de la Babilonia del exilio, las había de llevar desde el polvo hasta el perfume ofrendado al Señor por su santa titular, tema éste luego iconográfico de su heráldica y su sigilografía.

Además de la pobreza y la obediencia, las imponía una clausura integral en sus conventos, no pudiendo dejar el suyo sino para ir debidamente a otro de su misma orden. El ayuno, consistente en hacer una sola comida, duraba desde la Cruz de Septiembre hasta Pascua, menos los domingos, y durante el otro período eran también días suyos los de rogativas, témporas, las vigilias de Pentecostés, San Juan Bautista, los Santos Pedro y Pablo, Santiago, San Lorenzo, San Bartolomé y la Asunción y todos los viernes. Estos últimos, y durante el adviento, la cuaresma, las témporas y las vigilias, se guardaba abstinencia. En el refectorio se observa silencio y había siempre lectura. Para las enfermas, débiles y viejas, habia una remisión expresa a la Regla de San Benito, y para la colación y lección posterior a las vísperas a las constituciones cistercienses.

El silencio era la norma común, salvo en el parlatorio y con licencia prioral, además de la presencia de otras tres hermanas viejas y pías, si bien aquélla podía también concederse en otros lugares -"junto a las ventanas" era la expresión tópica insistente-con alguna motivación y era tácita en la estancia de trabajo para las conveniencias de éste.

Del hábito ya dijimos. $Y$ tanto las legas como las hermanas habian de cortarse el pelo ocho veces al año, concretamente para Pascua, Pentecostés, San Pedro, Santa Magdalena, la Natividad de la Virgen, Todos los Santos, Navidad y la Purificación.

La disciplina penitencial es casuística, detallándose las infracciones leves (vg., ofensa a otra hermana, negligencia en el canto), castigadas con un salmo; las medianas (vg., faltar al capítulo o al coro) con muchos salmos y una disciplina, para ello impuesto en el capítulo; las graves (desobediencia a la priora o subpriora, o atraer habitualmente con los ojos la atención de los hombres), con tres disciplinas en el capítulo y ayuno a pan y agua; las muy graves (vg., lesionar a otra hermana) que llevaban consigo una remisión al prior, prepósito o capítulo general, y las más graves, tipificadas por la inco- 
rregibilidad, a las que se aplicaba el encarcelamiento, y la expulsión para las que hubieran abandonado el convento.

La clausura de las hermanas era total para los hombres -exceptuados solamente los cardenales, obispos y legados-, incluidos los hermanos, con las salvedades de rigor pero extremadas, pudiendo por ejemplo el prior provincial hacer una visita a la misma una vez al año y también con las cautelas consabidas.

Cautelas también estaban previstas para la enajenación de los bienes, y como representantes al exterior de cada casa, se instituían cuatro seglares, por supuesto temerosos de Dios.

Las hermanas podían ser huéspedes de otras casas, donde había de recibírselas como tales, siempre que les diesen licencia para ello el prepósito o el provincial, y nunca atendiendo a invitaciones particulares.

No podían ser admitidas, para su rehabilitación, las menores de once años, tope que nos resulta elocuente, máxime si tenemos en cuenta tratarse de paises de clima frío. $Y$ aun así, para las menores dichas se preveía una cierta tutela de las Magdalenas, hasta su llegada a tal edad, sobre sus curadores fuera de la clausura y ad hoc.

La priora era elegida por las más viejas(19) y prudentes de las vírgenes que a su vez hubieran sido designadas cual electoras por la comunidad entera, requiriéndose la confirmación del prepósito. Idéntico sistema era el de la elección del prior de los hermanos, mas con ninguna referancia a la condición de los mismos en la comunidad, por no darse entre ellos diferencias. Teniendo en cuenta la distinción en las féminas entre las arrepentidas y las otras, no cabe duda tratarse de un nudo gordiano.

Trascendente, si se coteja con otras reglas monásticas y medievales, es la obligación del trabajo manual. El principio es la constante evitación de la ociosidad, de manera que, al arbitrio de la priora, había que dedicar al mismo tiempo no invertido en la oración, el canto, la lectio divina e incluso el cultivo intelectual de la materia sacra, previsto expresamente, lo cual también merece ser subrayado. Había hermanas que se turnaban semanalmente en la elección de las lecturas. También hay que fijarse en la hora libre para la meditación u oración individual concedida a cada una después de las completas y los nocturnos. Y en la posibilidad de recitar en la estancia del trabajo prima, tercia, sexta y nona.

$Y$ en fin, cual una clave espiritual, se exhorta a las monjas a la fidelidad a su condición, manifestada concretamente en la observancia de la regla misma y los estatutos y la obediencia a los superiores, y en hacer seguir siempre la penitencia a cualquier pecado cometido. Concluyéndose con la exhortación petriana ${ }^{(20)}$ a la vigilancia contra el enemigo. 
Penitencia que en el caso de las arrepentidas tenía tras sí una materia personal muy concreta. La cual era en cambio genérica, tanto en la expiación de las culpas propias cual en la intercesora de las de los demás, en el de sus hermanas de comunidad y de orden vírgenes. Equilibrio diferencial que tipificaba la familia religiosa. Pero que no perduró sin más.

Lo que nos lleva a algunas consideraciones comunes, a la vera de ciertos ejemplos concretos.

\section{UNA MUTACIÓN HACIA LO INDIFERENCIADO, DESDE LAUBAN}

La Cartuja y la Camáldula son parejas formas de vida monástica singularizada por la simbiosis de las variantes eremíticas y cenobítica en sus individuos y comunidades. Pero así como los cartujos no han conocido alteración a la tal, ni en las unas ni en los otros, los camaldulenses han acabado admitiendo casos de eremitismo o cenobitismo sin más, de manera que los dichos desposorios de ambas maneras se pueden predicar sólo del conjunto de sus familias religiosas(21).

$Y$ un fenómeno semejante es el que se dio en las Magdalenas ya desde fines del siglo XIII, habiendo podido contribuir a él la afluencia a sus casas de vocaciones de vírgenes aristocráticas y poderosas, a propósito de cuyas consecuencias hubo de llamar la atención otro legado pontificio Hugo de Saint Cher.

Teniendo lugar ya claramante la desnaturalización en una fundación llamada mucho más tarde a desempeñar un papel decisivo en la última etapa, la de supervivencia, de la historia de la Orden, Lauban(22), en la diócesis de Meissen, llevada a cabo por el duque Enrique y su mujer Inés, ésta hija del rey Wenceslao II de Bohemia. Era descendiente de Enrique I(23), el fundador con su esposa santa Eduvigis del monasterio cisterciense femenino de Trebniitz, y cuya nuera, la santa duquesa Ana(24), había fundado las clarisas de Breslau, y él también el de canónigos regulares agustinos de Naumburg.

Lauban fue fundado por Enrique en 1320, exclusivamente para vírgenes, siendo tanto más de notar ello por cuanto la nueva casa se constituyó como filial de otra preexistente, la de Naumburg de Queis, y lo mismo que ella con derecho de patronato sobre la parroquia local, a la cual quedó vinculada.

Y sin embargo, la elección de las Magdalenas por Enrique, apartándose de la tan densa tradición familiar en ese ámbito, y optando por una orden nueva y singular, parece obedeció a una compulsión expiatoria personal. Ello lleva consigo su visión de las mismas como diferenciadamente intercesoras a los tales íntimos efectos, a pesar de carecer la neonata casa de las arre- 
pentidas tipificadoras. Lo cual desde luego no es tener en cuenta, en la historia de la vida religiosa consagrada sin más, el peso de las mentalidades de las generaciones que se van sucediendo en el seno de sus diversas encarnaciones, de los ideales primigenios y las tradiciones de su historia concreta, aun no respondiendo ya literalmente a sus renovadas vicisitudes. Una impronta que, por otra parte, al incidir sobre unas formas de existencia siempre acusadamente diferenciadas en el conjunto de la sociedad, es susceptible de determinar formas de actuación y pensamiento de indiscutida trascendencia, mucho más allá de la repercusión, con tener ella también entidad, de un mero nombre.

Y notemos estar todavía dentro de la Edad Media cuando la tipificación se desvaneció. Sobre cuya cronología, y las posteriores hasta la contemporaneidad, hemos de hacer las consideraciones finales.

\section{¿ANACRONISMO O IMPACTO DE LAS CONTINGENCIAS?}

Así las cosas, las Magdalenas atravesaron el umbral de la Edad Moderna, con las consabidas pérdidas de casas y personas determinadas por impacto de la Reforma en su geografía, manteniéndose en esa subsistencia mixta de sus propósitos específicos y el acomodamiento a una manera de vivir religiosa más genérica.

Y cuando les llegó el turno bibliográfico o iconográfico en la histoire des ordres monastiques, religieux et militaires et des congregations seculaires de l'iun et de l'autre sexe qui ont ete establies jusqu'a a present, de Hélyot(25), éste llegó a tiempo aún de tratar, junto a ellas de bastantes supervivientes de esas otras "magdalenas" medievales anteriores a la constitución de esta nuestra orden propia de que empezábamos diciendo, a saber las Magdalenas o "Madelonettes" de París, Rouen y Burdeos; y las convertidas de Roma y de Sevilla, y sobre todo las de la capilla de San Jorge en la calle Saint Denis de París, llamadas popularmente Damas de San Maglorio(26), de quienes da a entender molestarse por la confusión a que su nombre y tradición podría dar lugar, de ser efectivamente todavía "arrepentidas", lo cual es la prueba más inequívoca de la desnaturalización integral que en su caso la institución había sufrido.

$Y$ de las Magdalenas propias -las Blancas Damas- "hace tiempo que, en la mayoría de sus monasterios, sólo se admiten las filles d'honneur.

Pero en algunas de las viejas casas aisladas fuera de la Orden, aún había "arrepentidas", llamadas de San Lázaro, junto a las de Santa Marta, religiosas con algún impedimento para la profesión, por ejemplo el matrimonio, y las de votos solemnes. 
$Y$ ya en el nuevo régimen, las Magdalenas mostraron una tenacidad indefectible por sobrevivir(27). Del josefismo y la exclaustración salieron con la sola casa de Lauban(28), naufragando las tentativas de fundar desde allá otras(29), por las persecuciones empalmadas del kulturkampt, el nacionalsocialismo y el comunismo de Tito(30). dedicadas allí a los enfermos, sucesoras como tales de las Elisabetinas de Breslau, menester que prefirieron a otro puesto vacante, el educacional dejado por las Ursulinas, hubieron de dejar mucho de su tradición monástica-sustitución de las horas canónicas cantadas por el oficio parvo de la Virgen recitando; misa rezada con cánticos en alemán en su participación pasiva, abandonados el canto figurado y la música instrumental de antes. Frente urbano de guerra su mismo convento durante bastantes días en 1945, acabó totalmente incendiado, trasladándose al fin a Seybolsdorf, en la diócesis de Ratisbona.

Ahora bien, esta pérdida de la diferenciación de las Magdalenas, hemos visto que no se puede identificar con el tramonto de los ideales medievales en unos tiempos nuevos. A propósito de lo cual, recordamos lo que decíamos de congregaciones de la Edad Contemporánea que, mutatis mutandis, y pensamos en el palenque sociológico, surgieron con los mismos propósitos de aquéllas. Así, a partir de 1801 se fundaron en Burdeos las Hermanas de la Misericordia(31), en un régimen de mucha libertad, con sus religiosas sometidas al mismo género de vida de las jóvenes a quienes recogian, hasta el extremo de afirmar que su regla consistía en el reglamento de aquéllas. $\mathrm{Y}$, en contacto con las mismas, en 1818, en Laval, las Hermanas de Nuestra Señora de la Misericordia(32), con religiosas para dirigir a las arrepentidas y otras para trabajos domésticos, divididas las acogidas en "clases" de cincuenta para fomentar la vida de familia, y que no podían llegar a la profesión, aunque sí permanecer indefinidamente en las comunidades cuales "muchachas de confianza", a quienes el pueblo tenía por hermanas.

Un camino largo de Rodolfo de Worms a Marie-Charlotte-Thérèse de Lamourous y Thérèse-Agathe Rondeau, pero en la misma lid de ese mundo, ambivalente entre lo diferencial y lo común, de la fecunda consagración religiosa de la vida en la iglesia latina. Habiendo en todo caso, entre todas las Magdalenas, esa unidad suprema determinada por la comunidad en la expiación de las vírgenes y las prostitutas. peccatum meum contra me est semper, rezaba el versículo sálmico adoptado en la liturgia de las exequias. 


\section{NOTAS}

(1) A cual más instructivas las consideraciones a ese respecto de los indiscutidos historiadores del benedictinismo y el Císter, Knowles y Lekai.

(2) Congregaciones parejas surgieron todavía en ese florecimiento numérico de la contemporaneidad a que nos hemos referido, $y$ algunas de cierta popularidad de nuestras ciudades. Después del Concilio, a la decadencia de la coordenada vindicativa en la sociedad aunó una insistencia eclesiástica menor en lo penitencial, y ello situó el problema en un contexto diverso.

(3) A su imitación se fundaron otras en Rouen y Burdeos.

(4) Su fundación en 1618 llega a atractivo argumento; anónima Relation de la naissance et progres du monastere des madelonnetes (París, 1649). Ya en el nuevo régimen, hubo un convento parecido en Montpellier, el de las Soeurs madelaines, de 1824 a 1958 , pero desde el principio sin aquellas distinciones en la comunidad, y a partir de 1860 y sobre todo en el siglo XX, reclutada en distintas procedencias y no en las "arrepentidas".

(5) Véase, para otro caso, P. PANSIER, L'ouvre des repenties a Avignon du XIIIe au XVIIle siecle (París-Aviñón, 1910).

(6) R. NIDERST, Robert d'arbrissel et les origines de l'ordre de Fontevrault 9 Rodez, 1952). Sobre todo el fenómeno contiene muchos datos la extensa noticia de Angel MARTÍNEZ CUESTA en el "Dizionario degli Instituti di Perfezione" 5 (1973) 802-13.

(7) Avanzada la Baja Edad Media, en la casa de las Penitentes de la Beata María Magdalena, de Aviñón, al principio reservada a las prostitutas menores de veinticinco años, por estar aún muy expuestas a la recaída, se admitió también a las vírgenes, viudas e incluso religiosas de otras órdenes.

(8) G. SIGNORELLI, Viterbo nella storia della chiesa (I, Viterbo, 1907); para Roma, H. GRAUET, Johan Von Toledo (Munich, 1901); cfr. L. FRATI, La vita privata in Bologna del secolo XIII al XVIII (Bolonia, 1931) 184-7.

(9) Aunque se dieron otras, tal la de San Gil, para la casa más antigua de Montpellier, siendo la de Santa Magdalena de 1328.

(10) "Dizionario" cit. en la nota 6,812-3.

(11) Si bien en el marco de su actuación, otras volvieron con sus maridos o se casaron; relato del Analista dominico de Colmar, apud K. KOSTER, Mainz in der geschichte des reuerinnen-ordens, "Jahrbuch fur das Bistum Mainz (1948); cfr. A. SIMON, L'Ordre des "Poenitentes" de Sainte Marie-Madelaine en Allemagne au $13 e$ siècle (Friburgo, Suiza, 1918, Buchberger, 6). 
(12) J.J. KOUDELKA Le "Monasterium tempuli" et la Fondation Dominicaine de San Sisto, “Archivum Fratrum Praedicatorum" 31 (1961) 59-60.

(13) Tengamos en cuenta el caso de Fontevrault, en este punto inverso, por el predominio de las abadesas en el gobierno de las comunidades de los dos sexos, llegándose a lo que se ha llamado humillación masculina. Recordemos que su fundador, Roberto de Arbrissel, tuvo que ver con este movimiento rehabilitador de las prostitutas.

(14) No es completo el coloquio "Doppelkloster und andere Formen der Symbiose männlicher und wiblicher Religiosem im Mittelalter" (ed. K. Elm y M. Parisse; "Berliner Historische Studien" ed. Friedich-Meinecke-Instituder Freien Universität, 18, Ordens Studien, VIII; Berlín, 1992)

(15) Véase M. DE FONTETTE, Les religieuses a l'âge classique du droit canonique (Paris, 1967) 65-80.

(16) Cfr. T. NYBERG, Offebarungen birgittas über die ordensregel, "Kyrkohistorisk draskrift" 73 (1973) 40-57, y él mismo en "Festschrift Altomünster 1973" (Aichach, 1973) 19-34.

(17) Cfr., C. SCHEEBEN Beitrage der Teutonia in der zweitwn halfte des 13 Jarhunderst, "Archiv. der deutschen Dominikaner" 3 (1941) 7-95.

(18) H. GROTEFEND, Dlie bussenden schwestern der heiligen María Magdalena in Deustchland, "Mitteilungen des Vereins Für Geschichte und Altertumskunde" 6 (1981) 301-16; J. SCHUNCK, Die Reuerinnen (Paderborn, 1927); Brevis historia ordinis S. M. Magdalenae de poenitentia sub regula Sancti Augustini (Zagreb, 1982).

(19) Una selectividad ésta concreta que puede decirse constante en la tradición toda. De ahí que uno de los ejemplos que pueden hacernos pensar en ser una segunda época la segunda mitad del siglo $X X$ es la privación de su derecho de elección pontificia a los cardenales octogenarios decretada por Pablo VI, y que un historiador de la Iglesia calificó de "eutanasia eclesiástica".

(20) EP, v, 8

(21) Empleamos el plural teniendo en cuenta su división en varias congregaciones posteriormente.

(22) Buena monografía de P. SKOBEL, Das jungfrauliche kloterstift zur heiligen María Magdalena von der busse zu lauban in schlesien von 1320-1821 (ed., E. Piekorz; Stuttgart y Aalen, 1970)

(23) Su hijo Enrique II protegió otra fundación cisterciense masculina Heinrichau, teniendo a su propósito ciertos conflictos con el obispo de Breslau.

(24) A. KNOBLICH, Herzogin anna von schlesien 1204-1265. Erinnerung-Blatter zu irhem sechshundertjarhingen todestage (Breslau, 1865).

(25) III (1715; o sea uno de los volúmenes dedicados a las seguidoras de la Regla de San Agustín) 358-68, "de los Religiosos y Religiosas de la Orden de la Penitencia de la Magdalena, tanto en Francia como en Alemania"; las demás, ibid., 368-83. Bajo el primer epígrafe se trata ampliamente de la casa parisiense de la rue Saint Denis.

(26) Por haberlas cedido la casa los benedictinos homónimos. 
(27) Ph. HOFMEISTER, Die exemption des Maddalerinnenordens. "Zeitschrift der Savigny Stiftung für Rechtsgeschichte. Kanonistische Abteilung" 35 (1948) 305-29.

(28) Cfr. N. BACKMUND, Die kleineren orden in Bayern und irhe kloster bi zur sakularisation. (Windberg, 1974) 72-6.

(29) De ahí noticias como la de la existencia de una casa a las puertas de Berlín, en Teltow; Enciclopedia Espasa, 60 (1928) 619.

(30) A. HYTREK, Sophie von rohitsch und das stift vom gotteshaus studenitz (Studenitz, 1895).

(31) Subsistieron independientes hasta 1971; J. BALDE, Les dames de la misericorde (París, 1932).

(32) A. Pottier, La Mére Therese de la Misericorde de Laval, en souvenir du centenaire de la fondation (Laval, 1920). 